\title{
HEALTH IN TRANSITION
}

Translating developmental origins of health and disease science to improve future health in Africa

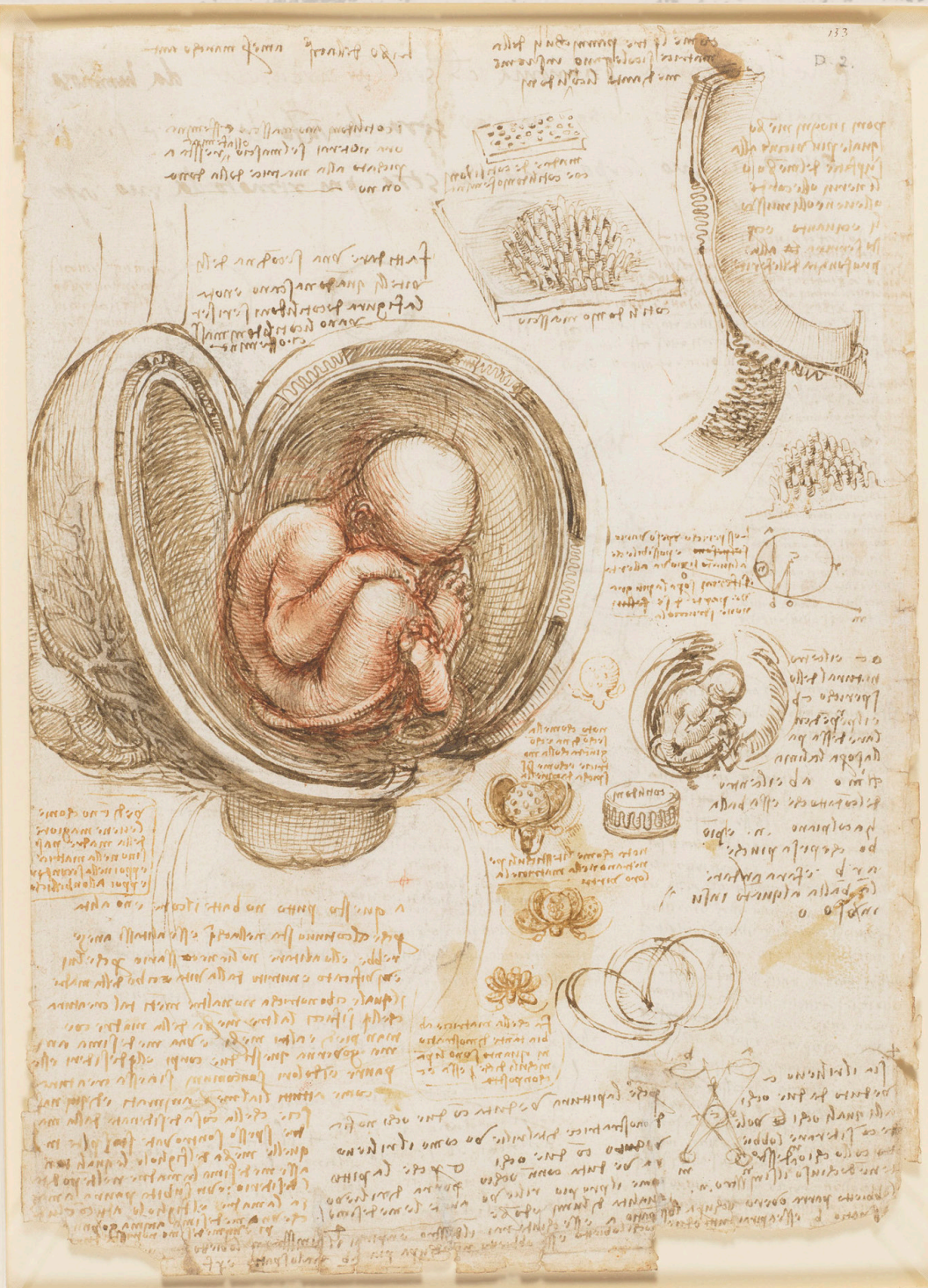

ANDREW J MACNAB, ABDALLAH DAAR \& CHRISTOFF PAUW 

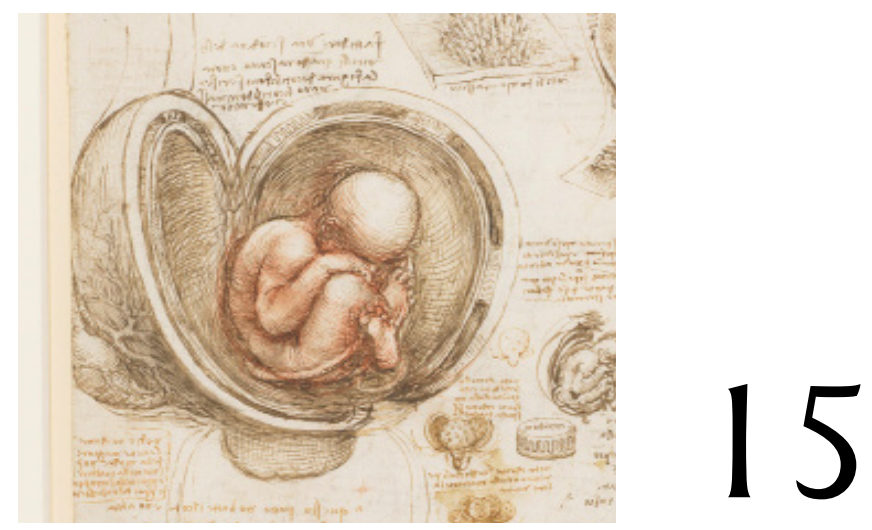

\title{
INTERSECTORAL APPROACHES TO HEALTH AND NON-COMMUNICABLE DISEASE PREVENTION IN AFRICA
}

\author{
Tolu Oni ${ }^{1}$
}

This chapter grounds efforts to achieve optimal population health in Africa, within the context of global and regional aspirations for health as part of the sustainable development agenda. The author highlights the important role that the rapidly growing urban centres in Africa are playing in the ongoing epidemiological transition, with an emerging non-communicable disease epidemic alongside a high burden of infectious disease. Far from seeing this only as a challenge, the author of this chapter explores the opportunity to harness this changing environment for health creation, propose a re-thinking of accountability for health towards a more inclusive definition of health services, and the role that adolescents can and should play both as important targets for non-communicable disease prevention and as agents of change, advocating for an all of government, all of society's approach to health.

1 MRC Epidemiology Unit, University of Cambridge, UK; Stellenbosch Institute for Advanced Study, Wallenberg Research Centre at Stellenbosch University, Stellenbosch, South Africa; School of Public Health and Family Medicine, University of Cape Town. 


\section{No sustainable development without health}

Emerging global policies and aspirations, including the New Urban Agenda and the United Nations (UN)' 17 'Sustainable Development Goals', encourage governments to 'leave no one behind', promote sustainable urban development, and to reduce inequalities. ${ }^{2}$

Two policy agendas for development at the global and Africa regional levels have raised awareness of the importance of understanding the interdependencies and interactions between different developmental challenges and the goal of improving population health and wellbeing, generating some momentum on the need for integrated approaches to addressing these.

The Sustainable Development Goals cover a broad range of social and economic development issues to be improved by 2030, from poverty, gender equality and health, to urbanisation, education and water. ${ }^{3}$ In the context of rapidly urbanising settings, meeting Goal 3, aimed to improve health and wellbeing, will require strategies focused on addressing the urban built environment exposures that drive ill health but could be harnessed to contribute positively to creating health. Such intersectoral strategies are an opportunity to re-think city development and planning processes, contributing to the achievement of Goal 11, which seeks to build resilient and sustainable cities, obtainable by the reinvention of human settlement.

The importance of incorporating non-communicable diseases into the broader global development policy agenda was underscored by the high-level meeting on non-communicable diseases at the United Nations General Assembly in September 2018. The draft political declaration submitted to heads of member states at this meeting underscored the importance of the interdependencies between sectors and the need for a life-course approach calling for a "scaling up of multi-stakeholder and multisectoral responses to the prevention and control of non-communicable diseases in the context of the 2030 Agenda for Sustainable Development".

2 United Nations (UN). 2016. The New Urban Agenda. Habitat III, the United Nations Conference on Housing and Sustainable Urban Development, 17-20 October. [https://bit.ly/2Qk4S3B]; UN Sustainable Development Goals (SDGs). 2020. About the Sustainable Development Goals. [https://bit.ly/3j9HToq]; UN, 2018. Time to Deliver: Accelerating our response to address NCDs for the health and well-being of present and future generations. UN General Assembly, September 27. Draft Political Declaration. [https://bit.ly/2YvkXYO].

3 Ibid.

4 UN. n.d. Overview of aspirations, goals and priority areas of Agenda 2063. Africa Union. [https://bit.ly/32x8d64]. 
This draft text recognises the importance of conducive environments for noncommunicable disease prevention and identifies the planning and development of cities as important to promote physical activity and sustainable healthy consumption and food production. The draft further includes the call for member states to:

Reaffirm the primary role and responsibility of Governments at all levels in responding to the challenge of non-communicable diseases by developing adequate national multisectoral responses for their prevention and control, and promoting and protecting the right of everyone to the enjoyment of the highest attainable standard of physical and mental health; and underscore the importance of pursuing whole-of-government and whole-of-society approaches, as well as health-in-all-policies approaches, equity-based approaches and lifecourse approaches. ${ }^{5}$

At a regional level, the Africa Union's Agenda 2063 sets out the development aspirations, goals and targets for 'the Africa we want' by 2063. In particular, the first aspiration for a prosperous Africa, based on inclusive growth and sustainable development, includes the interdependent goals for 'a high standard of living, quality of life and wellbeing for all citizens' ("including a priority for modern, affordable, and liveable habitats"), and for 'healthy and well-nourished citizens'. This long-term agenda is underpinned by a 10-year Science Technology and Innovation Strategy for Africa to accelerate Africa's transition to a knowledgebased economy. This strategy also recognises the prevention of non-communicable diseases in Africa as one of the six priorities. ${ }^{7}$

These global and regional goals highlight the importance of population health to achieve sustainable, inclusive development. However, as the next section discusses, these health needs are changing, driven by meso- and macro-level factors.

Figure 15.1 highlights key meso- and macro-level characteristics of the African context, that influence changing health needs and should inform efforts to improve health. These include the socio-political context of colonial history, migration, insufficient regional data-sharing platforms, and insufficient disaggregated data on health determinants and outcomes. This figure further highlights the consequences

5 UN, 2018.

6 African Union. n.d. Agenda 2063: The Africa We Want. [https://au.int/en/agenda2063/overview].

7 United Nations Population Fund (UNPF). 2007. State of world population 2007 Unleashing the potential of urban growth. [https://bit.ly/3aSl4CB].

(Accessed 27 December 2017). 
of this context and the role that research can play in improving health through place-based science.

For this chapter, the author will focus on two of these characteristics, rapid urbanisation, and the demographics to illustrate how the notion of health creation could be re-conceptualised.

\section{Africa's urbanisation threatens health gains}

Urbanisation is one of the most important demographic shifts worldwide, during the past century, and represents a substantial change from how most of the world's population has lived for the past several thousand years. ${ }^{8}$ It is a result of population migration from rural areas in addition to natural urban demographic growth. Many aspects of urban change in recent decades are unprecedented, including not only the world's level of urbanisation and the size of its urban population but also the number of countries becoming more urbanised and the size and number of huge cities. ${ }^{9}$ Since 1950, many urban changes have been dramatic - with the populations of dozens of major cities growing more than ten-fold, and many growing more than twenty-fold. Some of them sprawl for thousands of square kilometres. In 2007, the world's population living in towns and cities reached 50 per cent, and this proportion is growing. ${ }^{10}$ Today, more than half of the world's population resides in urban areas, more than the world's total population in $1960 .{ }^{11}$

African countries are rapidly urbanising. This urban transition is unfolding rapidly, with urban dwellers projected to exceed 50 per cent around 2035. ${ }^{12}$ In addition to the impact on the environment, unplanned and unmanaged growth across Africa, and high rates of poverty (62 per cent of urban dwellers live in slum conditions), are associated with exposures that contribute to and exacerbate, inequities in the burden of disease. ${ }^{13}$

8 Annual Reviews. 2005. Urban Health: Evidence, Challenges, and Directions. Annual Review of Public Health, 26:341-365. [https://doi.org/10.1146/annurev. publhealth.26.021304.144708].

9 Satterthwaite, D. n.d. The scale of urban change worldwide 1950-2000 and its underpinnings. [https://bit.ly/3lcNxIa].

10 UN. 2011. World Urbanization Prospects: The 2009 Revision. UN Population Division.

11 UN. 2014. World Urbanization Prospects: The 2014 Revision, Highlights. [https://bit.ly/2FTbynq]. (Accessed 22 May 2018).

12 UN Habitat. 2014. State of African Cities Report 2014: Re-imagining sustainable urban transitions. [https://bit.ly/2YuZOxJ].

13 UN Department of Economic and Social Affairs \& Population Division. 2011. World Urbanization Prospects: The 2009 Revision. [https://bit.ly/3gphS2z]. 
As two-thirds of the world's population will live in cities by $2050,{ }^{14}$ it will pose numerous challenges for African countries in meeting the needs of their growing urban populations, including housing, infrastructure, transportation, and basic services such as education and healthcare. Thus, more intriguing than these global figures are the ecological and socio-environmental conditions often associated with this urbanisation process. ${ }^{15}$ Rapid, unplanned and unsustainable patterns of urban development in Africa are making developing cities focal points for many emerging environmental and health hazards. ${ }^{16}$

The pace of change and the complex nature of urbanisation is contributing to this epidemiological transition across African cities.

The urban poor increasingly faces a 'triple threat' of injuries, infectious diseases, and non-communicable conditions (diseases) like diabetes and heart disease. ${ }^{17}$ In particular, residents of informal settlements typically face multiple risks due to:

hazardous shelter and local environmental conditions;

limited or non-existent access to safe water, sanitation, public transport, and clean energy;

insecure tenure and unsafe housing;

exclusion from affordable, high-quality healthcare, education, refuse collection, and other vital services;

spatial segregation; and

violence and insecurity.

Multi-faceted intersectoral efforts are crucial to respond to these interrelated challenges. There is also a plausible connection between urbanisation and the rising levels of non-communicable diseases in those countries. These exposures - individual, household and neighbourhood-level - influence behaviours (what people eat, their physical activity, whether they smoke or drink, isolation or

14 Fotso, J.C. 2006. Child health inequities in developing countries: differences across urban and rural areas. International Journal for Equity in Health, 5:9.

[https://doi.org/10.1186\%2F1475-9276-5-9].

15 Galea, S. \& Vlahov, D. Urban health: evidence, challenges, and directions. Annual Review of Public Health, 26:341-365. [https://bit.ly/2FSGuUR].

16 WHO \& UN Habitat. 2016. Global report on urban health: equitable healthier cities for sustainable development. World Health Organization. [https://bit.ly/311Z8Na].

17 WHO. 2015. Non-communicable diseases prematurely take 16 million lives annually: WHO urges more action. [https://bit.ly/31oymnp].

Intersectoral approaches to health and non-communicable disease prevention 
connection) and disease burden (water and air pollution-related diseases), lie largely outside the health sector.

These behaviours are exemplified by the rise in obesity, hypertension, and diabetes, associated with the increasing exposure of urban dwellers to unhealthy food, and human settlement environments that limit physical activity in cities. Furthermore, a rise in dense unplanned settlements with inadequate urban infrastructure, increased exposure to air, water, and noise pollution and unhealthy home environments are contributing to the increasing prevalence of chronic respiratory, and cardiovascular disease.

\section{The double burden of non-communicable and communicable diseases in Africa}

Non-communicable diseases are emerging in the context of rapid urbanisation and globalisation in low- and middle-income countries, especially amongst the poor residing in urban settings.

Non-communicable diseases refer to a group of diseases not mainly caused by an acute infection, resulting in long-term health consequences and often creating a need for long-term treatment and care. ${ }^{18}$ The World Health Organization (WHO) reports non-communicable diseases to be by far the leading cause of death in the world, as non-communicable diseases kill 38 million people each year and disproportionately affect low- and middle-income countries where nearly threequarters of non-communicable disease deaths - 28 million - occur. Cardiovascular diseases account for most non-communicable disease deaths, or 17.5 million people annually, followed by cancers ( 8.2 million), respiratory diseases (four million), and diabetes ( 1.5 million). ${ }^{19}$ These four groups of diseases account for 82 per cent of all non-communicable disease deaths. Of these 'premature' deaths, 82 per cent occurred in low- and middle-income countries in Asia and Africa. ${ }^{20}$

18 Mozaffarian, D., Fahimi, S., Singh, G.M., Micha, R., Khatibzadeh, S., Engell, R.E., Lim, S., Danaei, G., Ezzati, M., Powles, J. and the Global Burden of Diseases Nutrition and Chronic Diseases Expert Group. 2014. Global sodium consumption and death from cardiovascular causes. The New England Journal of Medicine, 371(7), August:624-634. [https://doi.org/10.1056/NEJMoa1304127].

19 Ibid.

20 Hunter-Adams, J., Nguendo Yongsi, B., Dzasi, K., Parnell, S., Boufford, J.I., Pieterse, E. $\&$ Oni, T. 2017. How to address non-communicable diseases in urban Africa. The Lancet Diabetes \& Endocrinology, 5(12), December:932-934. [https://doi.org/10.1016/S22138587(17)30220-6]. 
Risk factors such as a person's background, lifestyle and environment are known to increase the likelihood of non-communicable diseases.

The high burden of infectious disease in Africa has, for many years, been the focus of attention for interventions to improve health in the region. However, alongside this persisting infectious disease burden, African countries are experiencing a simultaneous growth in the burden of non-communicable diseases. ${ }^{21}$ For example, the burden of diabetes in Africa is expected to increase by 110 per cent between 2013 and $2035 .^{22}$

This rising burden of non-communicable diseases places an ever-increasing burden on government resources already strained by efforts to manage infectious diseases such as HIV/Aids, tuberculosis and malaria, with an ever-increasing budget required for the healthcare sector to treat and manage diseases adequately. At the level of the individual and household, the higher burden of these diseases in lowincome households is associated with catastrophic healthcare expenditure and loss of income, making addressing this emerging non-communicable disease epidemic a priority in Africa.

Thus, though the growing problem of communicable and non-communicable diseases is a particular problem for the urban areas in Africa, and while studies have begun to measure this burden of disease, there is a paucity of research seeking to address these urban health challenges using a systems approach.

\section{The need to harness Africa's urbanisation for health}

The scale and pace of urbanisation and the accompanying emerging noncommunicable disease epidemic in Africa makes improving African health crucial for achieving global Sustainable Development Goals. Thus, there is a pressing need to prioritise non-communicable diseases and for innovative new approaches to create health and prevent disease at the population scale. As much of the change in Africa's epidemiological profile is being influenced by the rapid rate of urbanisation, the built environment plays a significant role in non-communicable disease risk. It, therefore, can and should play an important role in the creation of health and prevention of non-communicable diseases.

21 Peer, N., Kengne, A.P., Motala, A.A. \& Mbanya, J.C. 2014. Diabetes in the Africa region: An update. Diabetes Research and Clinical Practice, 103(2):197-205.

[https://doi.org/10.1016/j.diabres.2013.11.006].

22 Patton, G., Coffey, C., Cappa, C., Currie, D., Riley, L., Gore, F., Mokdad, A., Degenhardt, L., Richardson, D., Astone, N., Sangowawa, A.O. \& Ferguson, J. 2012. Health of the world's adolescents: a synthesis of internationally comparable data. The Lancet, 379(9826):1665-1675. [https://doi.org/10.1016/S0140-6736(12)60203-7]. 
African countries are urbanising largely into conditions of informality, characterised by high poverty rates, and poor housing conditions. The increasing availability of processed foods high in sugar, trans-fats and salt, accompanied by poor access to spaces for transport- and leisure-related physical activity, rising outdoor and noise pollution are contributing to rising prevalence of obesity and diabetes, hypertension and cardiovascular disease, injuries, and mental disorders. Unaddressed, this rising non-communicable disease burden will have significant resource implications for African countries, already unable to cope with healthcare and economic costs.

Strategies to address non-communicable diseases in Africa to date have predominantly focused on improving treatment and screening to detect disease. While these are important, there is a need for a greater focus on prevention strategies that act on the upstream determinants of non-communicable diseases in African cities, highlighting the importance of building a knowledge base for the development and implementation of population-level, sustainable, equitable noncommunicable disease prevention strategies across the life-course.

Despite the obvious importance of health and wellbeing in sustainable urban development strategies, at local levels, health is largely not considered within these agenda, partly due to the siloed vertical nature of policymaking, resulting in a lack of policy coherence between health and health determinant sectors. Inequities in the exposure to health determinants that increase the risk for non-communicable disease, particularly in the urban poor are thus exacerbated by the disconnect between the public health and built environment sectors such as urban planning and food systems.

Cities can play a vital role in addressing health and social inequity; greater coordination across sectors could contribute to improving health outcomes. The rapidly evolving and growing nature of African cities is often cited as driving informality. Ill-health also represents an opportunity for innovative approaches to non-communicable disease prevention. This shift in approach requires shifting to a health creation paradigm across government and society.

Such interventions should target the physical and policy environments and societal norms that shape the conditions in which people live and work, requiring coordination across health and non-health sectors, given that the majority of exposures that influence non-communicable disease risk lie outside the health sector.

New approaches to health creation are needed to achieve this. Over and above individual-level interventions, population-level, long-term non-communicable disease prevention strategies are needed, engaging sectors that play an important role in the health and wellbeing of urban dwellers, particularly the urban poor. 


\section{The need for intersectoral approaches}

Understanding the key factors and inter-related determinants, contributing to a healthy city is important to effectively impact on the inhabitants' and communities' health and wellbeing in a changing urban environment. Without intervention, these patterns of urbanisation will continue to have significant detrimental effects on the health of urban communities, their environments and the planet.

The global and regional goals and aspirations presented in the first section of this chapter will not be achieved unless national and local governments commit to translating global policies into practice. Furthermore, coordination and cooperation across sectors through local intersectoral action is essential, as the underlying factors determining health, largely fall outside the scope and reach of the health sector.

Despite Africa's pressing need for this approach, urban health and urban health equity have not emerged as major research and policy priorities on this continent; with many African countries lagging in the area of urban health equity and healthy city initiatives. There are significant knowledge gaps in how global policies for improving health and wellbeing can be implemented to promote intersectoral action for non-communicable disease control in the African urban context. Moreover, how the global agenda is intersectional reflected in the national and subnational policies, particularly in Africa, is not yet fully understood, representing a major gap given the high and complex burden of disease and high levels of health inequity in the region. There is a need for all of Africa to shift to a paradigm of health creation, not just disease prevention and treatment while being responsible custodians of the planet.

Given these contexts, in addition to the conventional health systems designed to protect the health, there is a need for research into systems for health; creating knowledge on aligning urban systems and policies for the creation of health.

Figure 15.2 exemplifies this notion. While healthcare is traditionally considered a health service, the fact that the food, water, waste, habitation and transport services and sectors are vital determinants of health, means we could consider these as health services, working together with the healthcare sector to create population health and reduce the need for healthcare.

This work is starting to happen, with researchers in different parts of the continent starting to research urban health, including investigating changing patterns of disease in urban populations, and better characterising changing urban exposures. While these research activities have made great strides within their respective countries in generating evidence to inform public policies, the lack of collaborative 
efforts has resulted in missed opportunities to accelerate the pace of knowledge generation and experimentation through shared learning and comparative research in different African city contexts.

There is, therefore, a need for multi-stakeholder dialogue platforms (involving the public, private and civil society sectors) and mechanisms to support intersectoral (transversal whole-of-government) policy action plans. Such spaces are vital to bridge the gap between those working to address the knowledge gaps (researchers), actors responsible for implementation at scale (policymaker and practitioners); and the potential beneficiaries of, and advocates for, these interventions (civil society). This collaboration would serve to share information including on lessons learned relating to the implementation of intersectoral policies and strategies, to identify priority areas for research and intervention, and to strengthen the evidence base on best practice to prevent non-communicable diseases.

\section{What does this have to do with early life?}

\section{Adolescence as an important period in the life-course for non-communicable disease prevention}

Cognisant of the demographic context of the region, given that most behaviours that drive non-communicable diseases are formed in this life period, the demographic youth bulge in Africa means adolescents and youth represent an important target population for non-communicable disease prevention.

Adolescence (10-24 years) is a transitory period accompanied by physical, psychological and social development, and by increasing socialisation with peers and independence outside of the family. ${ }^{23}$

Unlike early childhood, exposures and experiences are not completely under the control of, or fully characterised by household characteristics, as adolescence start to explore their identity. Despite the tendency for adolescents to focus on immediate benefits, the health-related behaviours, such as diet and physical activity patterns, obesity, tobacco, and alcohol, that influence the risk of major non-communicable diseases in adulthood usually start or are reinforced during adolescence.

23 Patton, G.C., Sawyer, S.M., Santelli, J.S., Ross, D.A., Afifi, R., Allen, N.B., Arora, M., Azzopardi, P., Baldwin, W., Bonell, C., Kakuma, R., Kennedy, E., Mahon, J., McGovern, T., Mokdad, A.H., Patel, V., Petroni, S., Reavley, N., Taiwo, K., Waldfogel, J., Wickremarathne, D., Barroso, C., Bhutta, Z., Fatusi, A.O., Mattoo, A., Diers, J., Fang, J., Ferguson, J., Ssewamala, F. \& Viner, R.M. 2016. Our future: a Lancet commission on adolescent health and well-being. The Lancet, 387(10036):2423-2478.

[https://doi.org/10.1016/S0140-6736(16)00579-1]. 
Thus, adolescence is a critical window in which the behaviours that will promote and maintain health across the life course are established. ${ }^{24}$ Also, adolescence offers an opportunity to improve preconception health, which may also lessen intergenerational non-communicable disease risk.

Health behaviours like diet and physical activity are shaped in part by structural factors including built and policy environments. ${ }^{25}$ There is, however, a paucity of understanding of the potential levers for intervention to influence adolescent diet and physical activity across socio-ecological domains from the household and neighbourhood environments, to the school environment, highlighting why this is an important phase for intervention to prevent diabetes and associated risk factors. However, for many adolescents, the need to prevent non-communicable diseases is not perceived as relevant to adolescent life given the long time-lag from behaviour to disease; making it difficult to meaningfully and sustainably engage adolescents on this issue.

\section{Focus on diet and physical activity}

Non-communicable diseases share common, interrelated risk factors in particular tobacco use, harmful use of alcohol, an unhealthy diet and lack of physical activity. Risk factors and causes of premature death in adulthood develop during adolescence and possibly even earlier. There is currently a global epidemic of risk factors for subsequent non-communicable diseases, particularly in low- and middle-income countries with the highest rates of adolescent overweight and lowest rates of physical activity. ${ }^{26}$

However, besides sexual and reproductive health, the majority of adolescents do not perceive a need for non-communicable disease prevention, nor do they routinely access health care or the health sector. There is, therefore, a need for strategies seeking to identify levers to impact adolescent health - that are not purely within the contexts of either the health sector, the household, or even purely within school grounds. Innovative strategies are needed to understand better how adolescents experience and engage with their built environments. Novel strategies to involve adolescents in effecting healthy change in their built environments, and to spark an

24 Green, L.W., Richard, L. \& Potvin, L. 1996. Ecological foundations of health promotion. American Journal of Health Promotion, 10(4), March-April:270-281. [https://doi.org/10.4278/0890-1171-10.4.270].

25 Patton et al., 2012

26 WHO. 2004. Global Strategy on Diet, Physical Activity and Health. Resolution WHA55.23, 57 ${ }^{\text {th }}$ World Health Assembly, Geneva, May. [https://bit.ly/3goK9X3].

Intersectoral approaches to health and non-communicable disease prevention 
interest in long-term strategies to improve their adult health. Such strategies would need to be multisectoral and participatory, recognising the interactions between environmental and economic factors, social norms and personal choice.

\section{Urban levers to improve adolescent diet and physical activity}

An increasing proportion of African adolescent resides in rapidly growing, often unplanned cities. The built environments they are exposed to are often not conducive for embracing health-promoting behaviour. Furthermore, many strategies focus on individual-level behaviour change interventions. However, the effectiveness of advice on changing individual behaviour for diabetes prevention is, therefore, limited by the ability to embrace these behaviours. With perceived low risk and relevance of diseases such as diabetes to adolescents, such individual approaches are likely to have even more limited effect. By contrast, the evidence presented in earlier sections of this chapter demonstrates the important role that these environments, meso- and macro-level determinants, largely outside the health sector, play in disease prevention through healthier environments. There is, therefore, an opportunity to harness these built environments to improve diet and physical activity of adolescents.

Obesity, unhealthy diets, and physical inactivity, for example, are universal issues for adolescents in both high and low-income countries. Introducing healthier behaviours and protective factors during adolescence can significantly change an individual's health trajectory into adulthood.

Beyond consideration of adolescents as a key population group in noncommunicable disease prevention in the context of their health outcomes and urban exposures, there is an opportunity to engage adolescents in the process of research (Figure 15.3). As citizen scientists, adolescents could participate in the collection of data on their urban environments, and how these inform or restrict their behaviours. By involving adolescents in research, such approaches to research could also serve to increase their agency and support their roles as advocates for change in their communities. Intersectoral approaches to health will require rethinking of accountability mechanisms for health; and informed, empowered adolescents can play an important role in advocating for this change.

\section{Conclusion}

This chapter situates efforts to improve population health in Africa within the broader context of strategies for sustainable development. The author highlights the rapid urban growth on the continent as a potential threat to achieving these 
goals by contributing to the burden of disease and health inequity, but also an opportunity to re-think governance for health. Such re-conceptualisation is framed around re-thinking accountability for health as not just within the healthcare sector, but across all sectors and services that determine health. Lastly, given the demographic youth bulge of the continent, the importance of engaging adolescents in non-communicable disease prevention efforts cannot be overemphasised. 


\section{Figures}

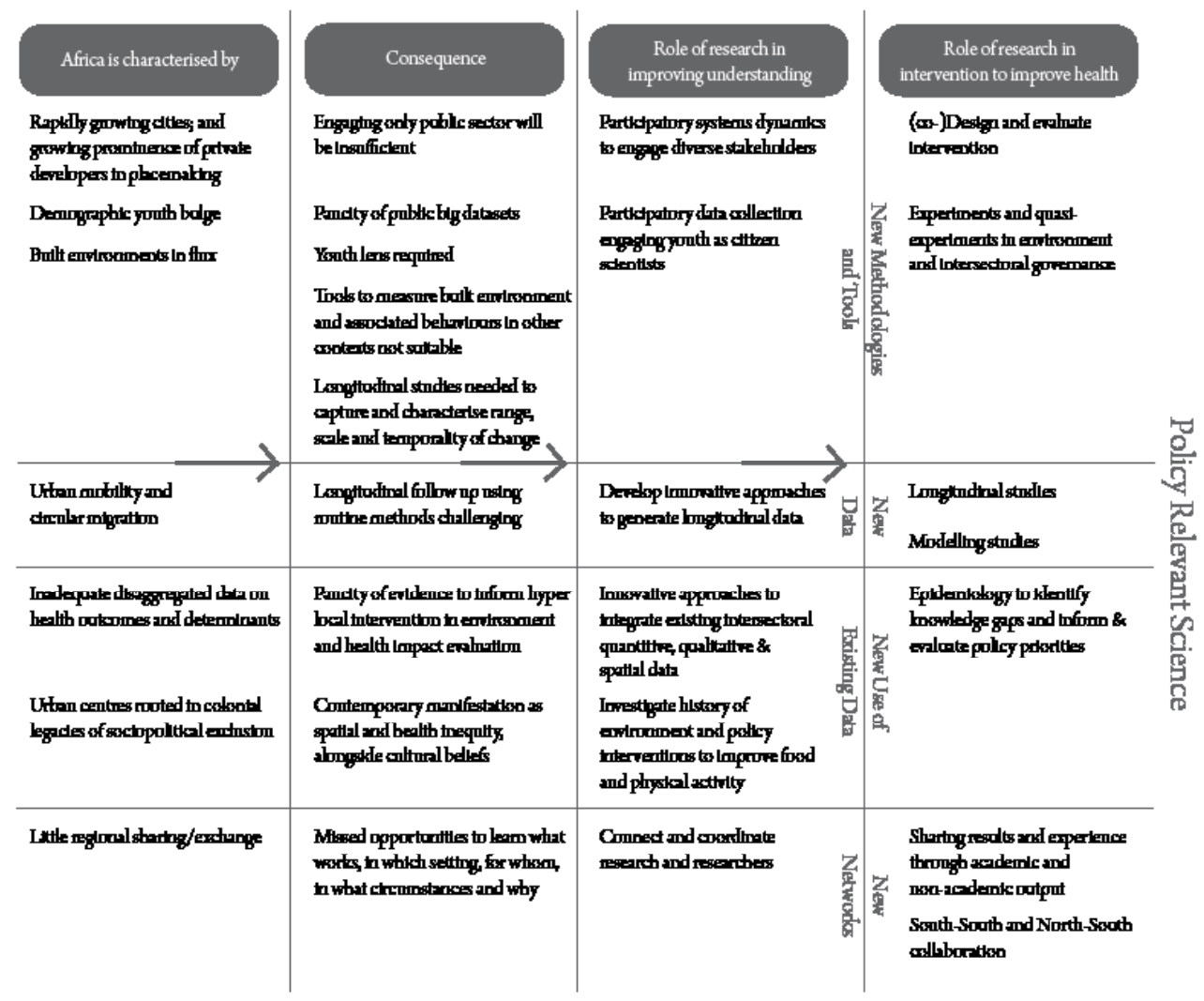

Figure $15.1 \quad$ Place-based context for policy-relevant science. 
City Services
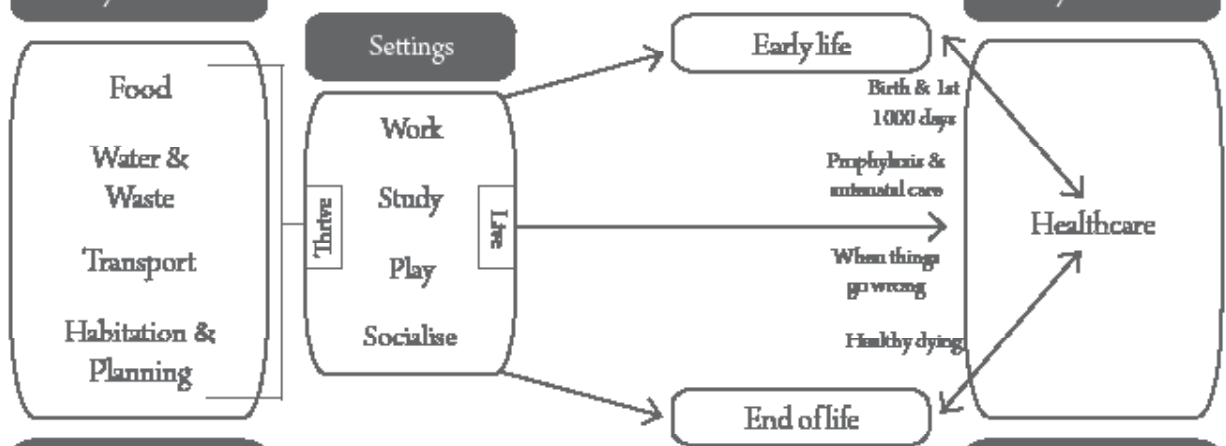

Health Services

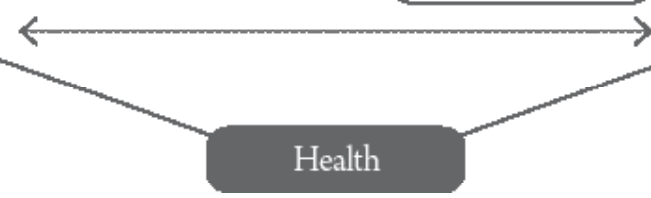

Health Services

Figure 15.2 Re-thinking (urban) health services - reducing the need for healthcare.

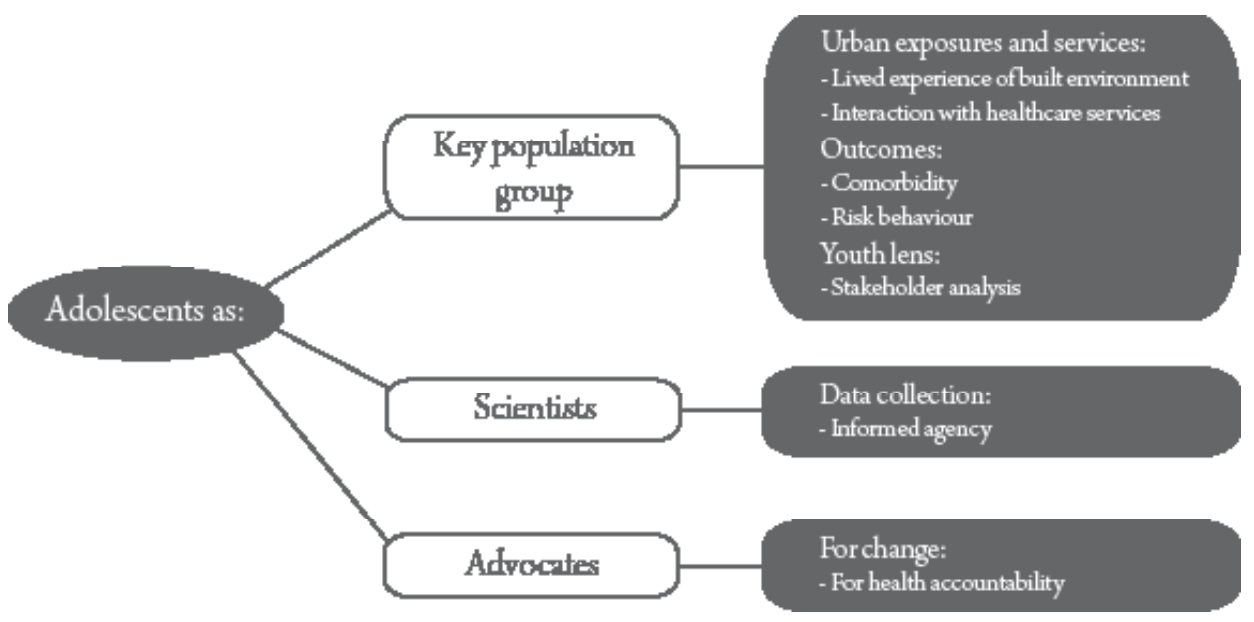

Figure 15.3 The roles of adolescents in non-communicable disease prevention. 